\section{Pediatria \\ COMPARAÇÃO ENTRE MARCADORES DE LESÃO RENAL EM CRIANÇAS GRAVEMENTE DOENTES: NECESSITAMOS REAVALIAR A DOSAGEM DE CREATININA?}

Herrero-Morín et al. (2007)' publicaram pesquisa com o objetivo de avaliar a função renal e as taxas de filtração glomerular (TFG) em crianças internadas em unidade de terapia intensiva (UTI). Foram selecionadas 25 crianças admitidas com qualquer quadro agudo em UTI de hospital terciário e que tinham necessidade do uso de sonda urinária, sendo exclusas crianças com doenças renais e tireodianas prévias e crianças com necessidade de terapia de substituição renal. Foram dosados no estudo creatinina, cistatina $C$, beta 2-microglobulina, clearance de creatinina e o clearance estimado pela fórmula de Schwartz. O conceito de disfunção renal aplicado no estudo foi o achado de um clearance de creatinina (dosado ou estimado pela fórmula de Schwartz) abaixo de 80 $\mathrm{mL} /$ minuto/I ,73 $\mathrm{m}^{2}$. Para análise estatística, foram utilizados o inverso da creatinina, da cistatina $\mathrm{C}$ e da beta 2-microglobulina para obter-se correlação com o clearance de creatinina e, para identificar o valor diagnóstico de tais marcadores para o clearance abaixo de $80 \mathrm{~mL} /$ minuto/l,73 $\mathrm{m}^{2}$, foram utilizadas curvas ROC (receiver operating characteristic curve), sendo maior a área abaixo da curva correlacionada com maior sensibilidade e especificidade para o marcador preditor da filtração glomerular.

Foram utilizados os valores de clearance tanto pela dosagem através da urina de 24 horas como pela fórmula de Schwartz. No primeiro caso, a dosagem de cistatina $C$ teve a maior área abaixo da curva ROC (com intervalo de confiança de 95\%) com o valor de $0,85 \mathrm{I}$, seguido pela dosagem de beta 2-microglobulina $(0,802)$ e por último a dosagem de creatinina $(0,633)$. Considerando-se a fórmula de Schwartz, os resultados são semelhantes. A dosagem de cistatina $C$ obteve área de 0,792 abaixo da curva ROC, a de beta 2-microglobulina 0,799 e a dosagem de creatinina obteve área de 0,625, ambas com intervalo de confiança de $95 \%$. A cistatina C neste estudo também obteve maior sensibilidade (85\%) e especificidade (63\%) para detecção precoce de disfunção renal quando comparada à creatinina (sensibilidade de $42 \%$ e especificidade de $54 \%$ ) e com resultados próximos à dosagem de beta 2 microglobulina (sensibilidade de $85 \%$ e especificidade de 54\%).

\section{Comentário}

A associação entre sepse grave elou choque séptico com algum grau de lesão renal é frequente e contribui de maneira importante para o aumento da morbimortalidade dos pacientes. É estimado que $23 \%$ dos pacientes com sepse grave e $51 \%$ dos pacientes com choque séptico com hemoculturas positivas desenvolvam quadros de lesão renal aguda². Múltiplos fatores, como a ação de citocinas pró-inflamatórias, a redistribuição de fluxo sanguíneo esplâncnico, o aumento importante da permeabilidade vascular e a potencialização da lesão renal secundária ao uso de medicamentos com toxicidade renal direta contribuem para o quadro descrito.

A determinação fidedigna da taxa de filtração glomerular (TFG) e a estimativa da função renal revestem-se de extrema importância. Os métodos universalmente disponiveis como a dosagem de ureia e creatinina possuem vários fatores que interferem em sua interpretação e comprometem a sensibilidade e especificidade das mesmas para predizer alteraçóes da função renal, fatores tais como massa muscular e seus fatores correlatos (idade, sexo e raça), ingestão de carne e altas doses de proteínas, obesidade, desnutrição e alguns medicamentos como trimetoprim, cimetidina e fibratos que reduzem a secreção tubular de creatinina. Além disso, o método mais utilizado na dosagem da creatinina (Jaffé modificado) é um método colorimétrico e a presença de cromógenos interfere diretamente na sua leitura (como nos casos de pacientes com icterícia importante), o que consiste em fator adicional a ser analisado.

A cistatina $C$, inicialmente identificada no final da década de 70, é uma proteína de baixo peso molecular com filtração livre pelos glomérulos, cuja concentração sérica é bem menos acometida por fatores extrarrenais como massa muscular, idade, sexo, utilização de medicamentos ou condições nutricionais quando comparada às dosagens de ureia e creatininat. Recentes estudos em crianças, em diversas situações clínicas, demonstram que a dosagem desta proteína correlaciona-se à maior precocidade, sensibilidade e especificidade para detectar alteraçóes na TFG medida por métodos convencionais ou por técnicas de medicina nuclear quando comparada à dosagem de uréia e creatinina, além de suas fórmulas correlatas para estimar a TFG. No estudo citado, foram consideradas admissões em UTI por qualquer quadro clínico e excluídas aquelas com doença tireodiana uma vez que há evidências de que doenças da tireoide interferem com a TFG e, assim, alteram os níveis de cistatina $C^{5}$. O autor obteve também a dosagem de beta 2-microglobulina, outro marcador caracterizado por filtração glomerular livre e ausência de reabsorção ou secreção tubular, com bons resultados semelhantes aos encontrados com a cistatina C. Na prática clínica, a dosagem de cistatina $C$ tem se mostrado de grande valor permitindo a ação precoce para a prevenção da lesão renal e deve ser estudada com maiores detalhes na população pediátrica, a fim de justificar sua instituição como método rotineiro, apesar do alto custo quando comparado à dosagem de creatinina.

Eduardo Mekitarian Filho

Professor adjunto livre-docente do Departamento de Pediatria da Universidade Federal de São Paulo/Escola Paulista de 
Medicina. Chefe das UCl's pediátricas do Hospital São Paulo, Hospital Santa Catarina e Pronto-Socorro/Hospital Infantil Sabará, de São Paulo, São Paulo, SP

Werther Brunow de Carvalho Médico intensivista do Pronto-Socorro/Hospital Infantil Sabará e Hospital Santa Catarina, de São Paulo. São Paulo, SP, Brasil

\section{Referências}

I. Herrero-Morín J, Málaga S, Fernández N, Rey C, Diéguez MA, Solís G, et al. Cystatin $\mathrm{C}$ and beta2-microglobulin: markers of glomerular filtration in critically ill child. Crit Care. 2007; I I(3):R59.

2.Schrier RW, Wang W. Acute renal failure and sepsis. N Engl | Med. 2004:351:159-69.

3.Laterza OF, Price CP, Scott MG. Cystatin C: An improved estimator of glomerular filtration rate? Clin Chem. 2002;48(5):699-707.

4.Stevens LA, Levey AS. Measurement of kidney function. Med Clin North Am. 2005;89:457-73

5.Fricker M, Wiesli P, Brandle M, Schwegler B, Schmid C. Impact of thyroid dysfunction on serum cystatin C. Kidney Int. 2003;63:1944-7. 